\title{
HERMENÊUTICA E PSICOTERAPIA
}

\author{
Maria Luísa Portocarrero
}

Universidade de Coimbra

C'est sur la dimension de l'être avec l'autre que repose la psychothérapie, et c'est en quoi elle se fonde sur la constitution de l'homme comme être-au-monde.

Henri Maldiney

\section{I}

Começo esta comunicação levantando uma questão: em que é que a conversão hermenêtica da fenomenologia pode contribuir para uma noção não positivista do humano e de psicoterapia? O que é a Hermenêutica filosófica? Um método de conhecimento, uma técnica de exegese de textos, uma variante da Fenomenologia? Ou a expressão de uma relação vital entre vida, significação e escrita, já descoberta pelos românticos e explorada por uma certa via da Fenomenologia, nomeadamente a de P. Ricœur. Escrevo para estar vivo, diz-nos Vergílio Ferreira, explicitando ainda que "um problema de missão é anterior ou "posterior' ao que escrevo". ${ }^{1}$ É de facto este tipo de missão implicada na relação estreita entre vida em sentido humano (a única que se faz um si mesmo) e escrita que a hermenêutica dá que pensar.

Comecemos então por compreender o que é a hermenêutica: ela adquire, pela primeira vez, uma dignidade filosófica com Fr. Schleiermacher, filósofo

1 Padrão, M, G., Vergílio Ferreira. Um escritor apresenta-se, Lisboa, Imprensa Nacional, 1981, p. 184. 
romântico e teólogo protestante e com W. Dilthey, o fundador da autonomia científica do mundo do espírito. Para os dois filósofos, a Hermenêutica era motivada pela questão do conhecimento do espírito humano, que já não podia ser explicado à maneira dos factos inertes, mas como algo que se compreende segundo o modelo de um texto. A hermenêutica representava uma forma de conhecimento peculiar, o método de acesso ao modo de vida absolutamente inefável e expressivo que é o humano. Os dois filósofos partilhavam uma preocupação comum: compreender o homem, pelos seus gestos expressivos, isto é, por meio das suas criações culturais. ${ }^{2}$

A vida humana, realidade descoberta pelo Romantismo e pelas filosofias da vida, acabava de ser desvelada como aquilo que escapa à objectividade e à perspectiva naturalista redutora do modelo explicativo das ciências naturais. Ela não podia entender-se de acordo com o modelo da imagem visual dos factos, pois a visão e a representação não captavam as nuances da sua dinâmica singular. Pelo que apenas podia compreender-se por meio da relação entre singularidade pessoal, texto e interpretação. A vida humana era já considerada como uma forma pessoal de alteridade que recusava qualquer redução à categoria da coisa inerte; ultrapassava a textura estática da representação, interpelava-nos; era pensada, em suma, como dinamismo que misteriosamente se faz significação. E fazia-o mediante a irrupção de estruturas comunicativas e simbólicas (texto), que indiciavam as suas peripécias e nos solicitavam, dando origem a uma nova ordem na realidade: aquela que é marcada pelo aparecimento da partilha, da dignidade, da linguagem e da história, fenómenos capazes de inaugurar o mundo do espírito, cujos universais eram de natureza intersubjectivo.

Tais são, de forma muito breve, os termos da questão hermenêutica nos finais do século XIX, século que acrescenta à universalidade da linguagem matemática, da prova e da verificação, a particularidade das línguas, das épocas, das singularidades pessoais e das nacionalidades. Percebe-se que o mundo da natureza não esgota o real e que esse outro mundo deve ser descoberto para além das verificações científicas; que é o mundo das relações humanas, um mundo marcado pela história, pelo texto, pelo enredo, pelo mal-entendido, pela transmissão e pela memória. Na opinião de Fr. Schleiermacher, o interesse de cada um de nós pela compreensão dos sinais do outro é de tal modo vital que o próprio intérprete tem a possibilidade de compreender o autor melhor do que ele se compreendeu a si mesmo. Também para Dilthey, a compreensão é um processo que parte de sinais psíquicos exteriores, desde a expressão fisionómica até aos sinais fixados de modo duradouro pela escrita, em ordem a chegar a um interior, com o qual deve coincidir e que não pode

2 Cf. Dilthey, W., "Origines et développement de l'herméneutique", in Idem, Le monde de l'esprit, Trad., Paris, Aubier, 1947, pp. 319 ss. 
perceber de outro modo. Coincidir e não reduzir, esta é a condição necessária da nossa compreensão de nós mesmos, dos outros e da própria felicidade.

No seu texto de 1900 sobre a natureza da hermenêutica e até aos seus últimos trabalhos, o filósofo sustentou que o quadro conceptual no interior do qual ele próprio procurava fundar as ciências humanas era o da Psicologia. Os problemas hermenêuticos situavam-se para si no interior do quadro da Psicologia recém criada, mas de uma psicologia ${ }^{3}$ descritiva e analítica, que precisava de se afirmar, como ciência autónoma, mediante um método sólido capaz de permitir objectividade e um estatuto digno para as ciências do espírito. Esse método era para ele o hermenêutico. Compreende-se o homem, explica-se a natureza, tal é a célebre máxima com que o filósofo consagra, na altura, o carácter estritamente metodológico da hermenêutica.

Com Heidegger, a Hermenêutica deixa o registo metodológico das ciências humanas ${ }^{4}$ e diz respeito ao modo de ser essencialmente temporal do existir, o único que, sendo mortal, levanta a questão, para ele próprio vital, do sentido e que é nele mesmo o paradoxo de facticidade e possibilidade. É com Heidegger que a facticidade da vida humana se converte no principal tema da Hermenêutica, que deixa claramente o registo tradicional para designar o modo de ser do ente que resiste a toda a tentativa de uma compreensão transparente. A hermenêutica do Dasein, o interpelado na questão do ser, descobre que este é mundano e temporal, que habita o mundo de modo hermenêutico e preocupado. ${ }^{5}$ Isto é, que é actividade e não representação, um projecto que se projecta para além de si confrontando-se constantemente com a significação do passado e nomeadamente com a dimensão outra do futuro; que compreender é para o Dasein ser, e que esta compreensão, que tem a forma da acção preocupada e do cuidado, parte de uma pré-compreensão logo, é anterior a toda a dialéctica metodológica e a toda a redução da linguagem ao primado da transparência.

A analitica existencial entra em cena a partir de então como via necessária para entender a questão nuclear trágica do existir, a da sua facticidade, isto é, a do seu ser uma experiência de contraste, logo uma questão fundamental: a do sentido do tempo, da possibilidade ou do ser. A hermenêutica ou interpretação é, antes de mais, um existencial fundamental, dada a natureza trágica do Dasein. Porque a compreensão (existencial fundamental, fundado numa compreensão prévia) é a revelação das possibilidades do Dasein - possibilidades nas quais ele já está jogado, muito antes de ter consciência disso -, porque ele não as pode explicitar a todas (é finito), ele é essencialmente interpretação, escolha e execução, que vai anulando algumas possibilidades e explicitando outras. Por outras palavras, continuo a ser um ser possível mas

3 Gadamer, H.-G. Gesammelte Werke X. Hermeneutik im Rücblick, Tübingen Mohr, 1995, p. 188.

${ }^{4}$ Cf. Heidegger, M., Sein und Zeit, Max Niemeyer Verlag, 1979, pp. 142-148.

${ }^{5}$ Cf. Idem, ibidem, pp. 66-88. 
nunca posso ser todas as minhas possibilidades. Daí a urgência da vida autêntica e o sentido da resolução como antecipação do ser para a morte.

\section{II}

Na linha do seu mestre, M. Heidegger, H.-G. Gadamer define a hermenêutica como a textura temporal do ser do Dasein, mas retoma a temática não valorizada por Heidegger, a da comunicação e da relação (ser-com) como existencial fundamental e tema nuclear da hermenêutica. Para o filósofo, a Hermenêutica é uma filosofia prática, na acepção aristotélica do termo, ${ }^{6}$ tem como objectivo reinventar para o Dasein os rituais da vida comunitária e ética, aqueles que o império da tecnociência e do mundo automatizado dos nossos dias obrigou a abandonar. Ela define, antes de mais, o modo como o homem habita o mundo, sempre mediado por tradições (narrações acerca da vida do homem em sociedade), símbolos, ritos, crenças e avaliações que lhe facilitam a compreensão crítica da sociedade actual, que lhe desenvolvem a criatividade e capacidade de crise, crítica e inovação, mostrando-lhe como é com o outro que conseguimos fazer sentido. ${ }^{7}$ A Hermenêutica representa a capacidade para ouvir criticamente o outro e não repetir automaticamente e para, neste ouvir, reconhecer como o outro pode dizer-me algo de novo e mesmo modificar-me. Por outras palavras, ser finito para Gadamer é ser marcado pela passividade da pertença fáctica a um horizonte de compreensão, já sempre recebido, horizonte que marca a nossa perspectiva. Partimos sempre de uma pertença à tradição, logo, de pressupostos e não de conceitos claros e evidentes, que possamos provar. E só a questão do outro, o encontro com o texto ou com a obra de arte questiona a nossa visão estreita (a partir de uma perspectiva) de mundo e faz-nos tomar consciência das nossas formas de compreensão prévias. Deste modo entendemos que só com o outro e em diálogo com as suas questões (o texto é resposta a uma questão que ainda hoje nos questiona) podemos desconstruir esquemas que nos dominam e descobrir com o outro a nossa real autenticidade.

A fenomenologia hermenêutica de Gadamer marca a condição dialógica da razão humana; a valorização do sentido positivo do preconceito assinala a inscrição do outro na minha passividade mais profunda; o modelo de inteligibilidade é para ele o da questão resposta, que pode conduzir ao diálogo de horizontes. ${ }^{8}$ Este diálogo leva-nos a construir, com o texto, com o outro,

${ }^{6}$ Cf., Gadamer, H.-G., Vernunft im Zeitalter der Wissenschaft, Frankfurt, Suhrkamp, 1980, pp. 78-109.

7 Cf. Portocarrero Silva, M., L., "O preconceito em H.-G., Gadamer: sentido de uma reabilitação", Lisboa, FCT/FCG, 2005

${ }^{8}$ Gadamer, H.-G., Gesammelte Werke. I. Hermeneutik I, Wahrheit und Methode I. Grundzüge einer philosophische Hermeneutik, Tübingen, Mohr, 1986, pp. 442-460. 
a comunidade de sentido que somos e pelo qual vivemos. A hermenêutica é enfim a arte de aprender a não ter sempre razão, a perceber que o mundo dos factos é sempre simbolicamente mediado, logo a dialogar com outro e com outros símbolos. "Ela não é apenas uma disciplina auxiliar que cumpre a função de uma importante ferramenta metodológica para todas as ciências. Penetra até ao mais íntimo da filosofia, que não é apenas pensamento lógico e investigação metodológica, mas persegue uma lógica do diálogo. O pensamento é a conversação da alma com ela mesma. Assim definiu Platão o pensar e tal significa, simultaneamente, que este é um ouvir as respostas que damos a nós mesmos ou que nos são dadas, quando trazemos até à questão o incompreensível. Entender o incompreensível e, sobretudo, entender o que quer ser entendido, engloba a totalidade da nossa capacidade de meditar, que oferece sempre, nas religiões, na arte dos povos, na torrente da nossa tradição histórica, novas respostas e desperta, com cada resposta, uma nova pergunta. Tal é a hermenêutica enquanto filosofia". ${ }^{9}$

Por meio dela podemos finalmente entender a grande diferença que existe entre mundo partilhado e mundo solitariamente habitado. Só na linguagem e seu poder dialógico as coisas podem realmente alcançar a sua objectividade, pois só nela deixam de coincidir apenas com o meu ponto de vista ou com o do outro, para se elevarem à dimensão do comum ou do universal, sempre a construir. A constituição linguística da nossa experiência do mundo, diz-nos Gadamer é realmente capaz de envolver as relações vitais mais diversas; ${ }^{10}$ "na linguagem torna-se evidente o que é real para além da consciência de cada um de nós"."

Daí a necessidade sentida pelo filósofo de reabilitar os pressupostos de toda a compreensão humana, como categoria antropológica e epistemológica central, mostrando-nos, contra a Modernidade científica e iluminada, que só os preconceitos, considerados pela Ilustração, como o principal motivo de erro e infelicidade, permitem hoje pensar o acesso sempre finito, múltiplo e diferenciado do homem ao sentido. ${ }^{12}$ Eles não são à partida juízos errados, mas categorias dialécticas que só no diálogo podem ou não vir a ser confirmados. Então, e este parece-me um dos temas mais importantes de Gadamer para a psicoterapia, enquanto análise, reconhecer que partimos sempre de preconceitos, na nossa compreensão, é o primeiro passo para percebermos o carácter provisório e processual dos nossos prejuízos. Quem se fecha nos seus preconceitos como conceitos definitivos e quer prová-los, aliena-se ou pode estar doente. Ou fazemos sentido com os outros ou não fazemos mais. Os preconceitos até podem, de facto, condicionar uma visão disfuncional de mundo e actuam em nós sem darmos por ela, como uma força exercendo-se nas nossas

9 Idem, Über die Verborgenheit der Gesundheit, Frankfurt, Suhrkamp, 1993, p. 205.

10 Idem, Gesammelte Werke. I Hermeneutik I, Wahrheit und Methode I., p. 452.

11 Idem, ibidem, p. 453.

12 Cf. Portocarrero Silva, M.L., op. cit. pp. 307-377. 
costas, mas com o outro posso aperceber-me do seu carácter provisório e ultrapassá-los pela construção de um novo esquema operatório. São as questões do outro que tornam para mim visíveis os meus preconceitos. O outro como tu transforma-se assim no verdadeiro medium da veracidade. A doença estará então na recusa do outro, no fanatismo e fundamentalismo.

Para Gadamer tudo o que existe, existe na relação com o outro: a verdade é profundamente dialógica e a hermenêutica sempre procurou este tipo de compreensão que exige a abertura ao outro, a desconstrução dos meus pressupostos por meio do encontro maiêutico com o outro, uma terapia de si mesmo, feita por meio do horizonte do outro, que me aparece nomeadamente por meio da aprendizagem do texto. Terapia que exige trabalho sobre si, a tradução do horizonte estranho para o meu, logo uma longa tarefa de formação do si.

De acordo com o filósofo, num dos seus textos, "Hermenêutica e psiquiatria", ${ }^{13}$ a hermenêutica ou arte de compreensão mostrou-se outrora importante em três grandes dimensões: na cura de almas, na interpretação da mensagem de esperança e conversão de vida própria da Bíblia e na jurisprudência com a sua interpretação das leis ${ }^{14}$ ou normas que estruturam a identidade que apenas se constrói na vida em comunidade. Mas a hermenêutica aplicada ao Mistério da saúde, sobre o qual o filósofo reflecte ainda, relembrando os seus diálogos com o médico F. von Waizsäcker, mostra aos técnicos da medicina e psiquiatria que esta nada produz como a ciência, nem pode ter os critérios metodológicos de verificação desta, porque está sempre situada entre ciência e arte, ${ }^{15}$ a arte de ouvir, de estar ao serviço, de dialogar, de interpretar e de acompanhar. O modelo da relação médico doente é para Gadamer o da aliança entre ciência e hermenêutica dos sinais da doença.

\section{III}

Com Ricœur a conversão hermenêutica da Fenomenologia atinge a maturidade e a hermenêutica tem como eixo central o poder de agir do existir, isto é, uma toda uma reflexão sobre a acção humana. Ricœur, é simultaneamente um filósofo crítico do cogito tradicional, um herdeiro da filosofia reflexiva e um crítico do naturalismo dos factos em psicologia. Esta é abstracta, pensa, enquanto não abordar o homem concreto, um corpo próprio apropriado mediante o esforço, o projecto e a decisão (querer é decidir ${ }^{16}$ ), e não perceber

13 Gadamer, H.-G. Über die Verborgenheit der Gesundheit, pp. 201-213.

${ }^{14}$ Idem, ibidem, p. 203.

15 Cf. Idem, ibidem, pp. 111-120.

${ }^{16}$ De acordo com a fenomenologia ricoeuriana da vontade (cf. Idem, ibidem, p. 187), uma vontade que apenas projecta é incompleta. Não é posta à prova; é a aç̧ão o critério da sua autenticidade. Uma vontade que não consegue mover o corpo e mudar por meio dele qualquer coisa no mundo, está muito perto de se perder em votos estéreis e no sonho. 
esta última como acto, o acto que nos obriga a realizar as coisas decididas, ${ }^{17}$. não de um modo arbitrário, mas sempre mediado por motivos ${ }^{18}$ que as justifiquem. Agimos, somos seres em acto, não porque uma causa nos obrigue, ${ }^{19}$ mas por meio de motivos que, enraizados na nossa espessura corporal, nos fazem mover o corpo. Nada causa uma decisão, mas um motivo pode justificá-la, tal é a tese do filósofo, que considera o novo sujeito como acto, acção e simultaneamente capacidade de padecer. E analisa o agir/padecer não à lupa mas a partir dos seus sinais, testemunhos, acentuando o primado da mediação reflexiva de si - sempre feita a partir do outro - sobre a posição imediata do sujeito tradicional.

A novidade de Ricœur reside justamente no seu desacordo face a toda a via curta da reflexão, seja a do cogito imediato moderno, seja a naturalista dos factos vividos, seja a da Daseinsanalyse. Para ele é no contexto de uma filosofia do agir, que parte da relação dialéctica do voluntário e do involuntário e dos testemunhos da vontade, ${ }^{20}$ que poderemos entender o humano e perceber como ele é marcado já não por um dualismo mas por uma desproporção interior, ${ }^{21}$ que o faz ser uma constante necessidade de atestação e testemunho. Tal desproporção e não o facto de sermos um corpo, é a real marca da dimensão finita do homem.

É o homem mistura e não coincidência consigo mesmo, uma realidade mista, ${ }^{22}$ porque feita da tensão de finito e de infinito, o cerne da concepção ricoeuriana de finitude. É esta a razão da fraqueza específica do homem, a ratio da sua falibilidade: não ser uma alma separada nem tão pouco um corpo simplesmente biológico. Ser corpo próprio, é ser uma mistura de finitude, que se transcende, e de infinitude, que se limita, é enfim um ser dotado de uma constituição ontológica desproporcionada e, por isso mesmo, frágil,

17 Cf. Ricœur, P., Philosophie de la volonté. Le volontaire et l'involontaire, Paris Aubier, Montaigne, 1967, pp. 45-46: "Entre tous les actes qui désignent pratiquement "ce qui est à faire', la décision, se distingue par deux traits . 1) Elle désigne catégoriquement 2) une action propre. Par la décision je prends position (Fiat! Que cela soit!); son caractère catégorique distingue la décision de la velléité qui vise ne action propre mais de façon évasive [...]."

18 Idem, ibidem, p. 64: "Pas de décision sans motifs!".

19 Quanto a esta importante diferença, entre motivo e causa e porque não podemos aqui desenvolvê-la, ouçamos o que nos diz o filósofo, na mesma obra, p. 65: "Le propre d'une cause est de pouvoir être connue et comprise avant ses effets [...]. C'est la cause qui confère son sens à l'effet. C'est au contraire l'essence d'un motif de n'avoir pas de sens complet en dehors de la décision qui l'invoque. Il ne m'est pas donné de comprendre d'abord et en eux-mêmes les motifs, et d'en dériver secondement l'intelligence de la décision. Leur sens final est lié de manière originale à cette action de soi sur soi qu'est la décision; d'un même mouvement une volonté se détermine et détermine la figure définitive de ses arguments affectifs et rationels, impose son décret à l'existence future et invoque ses raisons: le moi se décide en s'appuyant sur..."

${ }^{20}$ Cf., Idem, ibidem, pp. 202-207.

21 Cf., Idem, ibidem, pp. 212-213.

${ }^{22}$ Idem, Philosophie de la volonté. II. L'homme faillible. II. Finitude et culpabilité, p. 12. 
sempre maior e mais pequeno do que ele mesmo. ${ }^{23}$ Tal é a razão do seu sofrimento. Marcado, do ponto de vista ontológico, pela desproporção, pelo paradoxo e pelo desequilíbrio, o homem é, de facto, a porta de entrada do mal, da alienação e do sofrimento no mundo: "Não devo espantar-me se o mal entrou no mundo com o homem [...], ele é a única realidade que apresenta esta constituição ontológica instável de ser maior e mais pequeno do que ele mesmo". ${ }^{24}$ Misto de ser e de não ser, de finitude e de infinitude, é em si mesmo e não entre coisas separadas, sublinha o filósofo, que o homem é intermediário. ${ }^{25} \mathrm{O}$ seu acto de existir (esforço) possui uma textura estranha: ser um acto mediador, cujo modo de aparecer é realizar "mediações fora e dentro de si entre todas as modalidades e todos os níveis da realidade". ${ }^{26}$

Ser homem é, com efeito ser um ser frágil ou falível, cuja fragilidade pode inclinar-nos a sofrer e agir de forma alienada. Pode mas não inclina necessariamente. Ricœur é um filósofo da esperança, acredita no homem capaz de atestação de si, no homem capaz de se tornar um sujeito de direito e de lutar contra o mal. E se recusa o cogito exaltado de Descartes, toma também uma posição muito clara quanto às concepções filosóficas que reduzem e humilham o cogito. Rejeita ainda aquelas que consideram o homem perdido pelo facto de ser corpo e de estar lançado no mundo. Considera-o simultaneamente capaz de atestação de si e de alienação. Concebe-o, à maneira heidegeriana, como um ser que deve tornar-se no que é; se é um ser possível, precisa de se afirmar como vontade, isto é, como um si mesmo diferente dos outros e de dar testemunho, mediante os actos, das suas capacidades mais próprias que são, agora, eminentemente práticas e exigem a mediação do outro, na figura do tu e na das instituições, nomeadamente a linguístico-cultural e a jurídica e política.

Tais capacidades são capacidades de $\operatorname{agir}^{27}$ e analisar o agir exige que se parta da sua semântica própria, semelhante à de um texto, isto é, absolutamente resistente à análise causal dos factos. A semântica do agir é intencional, requer que se dê atenção à dialéctica da atestação ${ }^{28}$ e do testemunho; foge pois ao modelo da representação e do facto, compreende-se pela interpretação dos seus testemunhos significativos, significações essas que autonomizam a acção e instituem a sua dimensão histórica e social. ${ }^{29}$ Tal como um texto, "a acção humana é uma obra aberta, cuja significação 'está em suspenso'”. ${ }^{30}$

23 Idem, ibidem, p. 22.

24 Idem, ibidem.

25 Idem, ibidem, p. 14.

26 Idem, ibidem, p. 22.

27 Cf. Idem, Philosophie de la volonté. Le volontaire et l'involontaire, p. 53.

${ }^{28}$ Cf. Idem, "Le discours de l'action", in Tiffeneau, D. (ed.), La sémantique de l'action, Paris, CNRS, 1977.

29 Idem, Du texte à l'action. Essais d'herméneutique, II, Paris, Seuil, 1986, p. 193.

${ }^{30}$ Idem, ibidem, p. 197. 
Todos os acontecimentos humanos e todos os actos significativos estão, deste modo, à espera de novas interpretações que decidam da sua significação. Do lado do seu actor, implicam para cada um não a categoria de autor, mas a capacidade de se designar a si mesmo como sujeito dos seus enunciados, como autor das suas acções, como sujeito da história da sua vida e como um ser imputável ou responsável pelos seus actos. ${ }^{31}$

Tal é a traça da dignidade humana, o que diferencia o homem do âmbito dos factos, e o faz ser capaz de ser um quem. Um quem lê-se nos seus testemunhos e forma-se na apropriação da transmissão narrativa da história e da ficção. Ler-se a si mesmo diante do espelho que reflecte a humanidade, eis segundo Ricœur, a tarefa que cabe ao novo eu, que assim se forma no tempo humanizado que se desenvolve na narrativa. Que tempo é este afinal? O da iniciativa, da memória e do esquecimento, da promessa, do valor e da responsabilidade, o tempo público de uma vida particular, marcada pela pertença singular às representações simbólicas e às instituições.

Compreendemos pois que a analítica existencial de Ricœur difira da de Heidegger, e implique um enxerto da hermenêutica dos testemunhos humanos, isto é, dos símbolos, textos e narrativas, na fenomenologia. À analítica existencial Ricœur chama via curta, porque demasiado apressada e presa ainda ao modelo do ver: "Existem duas maneiras de fundar a hermenêutica na fenomenologia [...] a via curta [...] e a via longa, aquela que me proponho percorrer. A via curta é a de uma ontologia da compreensão, à maneira de Heidegger. Chamo via curta a uma ontologia da compreensão deste tipo, porque ela rompe com os debates relativos ao método e coloca-se imediatamente no plano de uma ontologia do ser finito, encontrando aí a compreensão enquanto modo de ser e não como modo do conhecer [...]. A via longa, que proponho, tem também como ambição elevar a reflexão ao nível de uma ontologia; mas irá fazê-lo por etapas, seguindo as exigências sucessivas da semântica [...] e em seguida da reflexão. A dúvida que expresso [...] diz apenas respeito à possibilidade de fazer uma ontologia directa, subtraída de imediato a toda a exigência metodológica". ${ }^{32}$

31

32

Cf. Idem, Le juste, Paris, Esprit, 1995, pp. 30-33.

Idem, Le conflit des interprétations. Essais d'herméneutique, Paris, Seuil, 1969, p. 10: "Il y a deux manières de fonder l'herméneutique dans la phénoménologie. Il y a la voie courte [...] et la voie longue que je me proposerai de parcourir. La voie courte c'est celle d'une ontologte de la compréhension, à la manière de Heidegger. J'appelle 'voie courte' une telle ontologie de la compréhension, parce que, rompant avec les débats de méthode, elle se porte d'emblée au plan d'une ontologie de l'être fini, pour y retrouver le comprendre, non plus comme un mode de connaissance, mais comme un mode de l'être [...]. La voie longue que je propose a aussi pour ambition de porter la réflexion au niveau d'une ontologie; mais elle le fera par degrés, en suivant les requêtes successives de la sémantique [...] puis de la réflexion. Le doute que j'exprime [...] porte seulement sur la possibilité de faire une ontologie directe, soustraite d'emblée à toute exigence méthodologique." 
É este o sentido da contestação ricoeuriana da Daseinsanalyse: esta deixava completamente de lado, apesar da sua extraordinária força de sedução, os problemas metodológicos suscitados pela distinção do que (facto) e do quem (pessoa), isto é, o desvio necessário pelas significações e instituições que balizam o agir humano, situando-o sempre num espaço público de sentido e interacção. Espaço este que estruturado pela linguagem, pelo texto, pela história e pelas instituições, virá a constituir o principal motivo da reconquista ética do $s o i$, logo o principal objecto da análise de Ricœur. Quer dizer: se o agir humano, apenas se diz pela mimese linguística da praxis, ele tem uma estrutura linguística, logo é preciso analisar os símbolos, signos e mythos que o dizem. Se todo o símbolo é signo, ele é um signo especial que, dada a sua dupla significação, tem a estrutura de um quase texto; é preciso então saber o que é um texto, como é que ele significa, e ainda discutir a sua redução à intenção psicológica do seu autor. O texto tem uma autonomia própria, abre-se a múltiplas interpretações, e é justamente, pela sua trama que surgem as potencialidades poéticas da linguagem na reorganização do Cogito, da sua auto-estima e da sua capacidade de agir. O que tem os seus efeitos na interpretação do modelo positivista habitual de apreensão dos fenómenos. ${ }^{33}$ Daí o grande cuidado do fillósofo com a problemática do texto, com o trabalho do texto, com a compreensão e com a explicação da relação entre a experiência do tempo vivido, a construção e a recepção dos enredos que o dizem.

A relação entre as experiências, efectivamente vividas das peripécias, que entretecem a condição do ser agente e sofredor ${ }^{34}$ e a necessidade da intriga histórica ou da ficção, como núcleo da sua ordenação intencional, é o eixo fundamental que permite entender o agir na sua historicidade. Entre a descrição e a prescrição, a narrativa prepara a adscrição de uma acção ao seu agente. Esta escapa a toda a análise eidética, porque é temporal e só uma empírica simbólica o pode dizer. Além disso, a narração tem um poder "psicagógico" importante, isto é, uma capacidade "de acordar os afectos e de suscitar por meio do verbo a força hipnótica das imagens". ${ }^{35}$

A via de acesso ao mundo do agir e do vivido, é então procurada na habitual transmissão das conversas ordinárias, nos símbolos, relatos ou narrativas que nos formam e educam na intencionalidade ética e temporal da condição quotidiana da pluralidade. ${ }^{36} \mathrm{O}$ que supõe, desde logo, uma total reavaliação da relação entre mito e filosofia ${ }^{37} \mathrm{e}$ ainda uma meditação sobre o efeito ontológico e configurador da figura literária da intriga e da inovação semântica.

33 Idem, Du texte à l'action. Essais d'herméneutique II, Paris, Seuil, 1986, p. 30.

34 Cf., neste sentido, Idem, ibidem, pp. 97 ss.

35 Ferry, J.-M., Valeurs et normes. La question de l'éthique, Bruxelles, éd. de l'Université de Bruxelles, 2002, p. 25.

36 Cf., neste sentido, Ricœur, P., Temps et récit, I Paris, Seuil, 1983, pp. 19-136.

37 Cf. Idem, Philosophie de la volonté. Finitude et culpabilité. II La symbolique du mal, Paris Aubier, 1960. 
Ao papel fundamental dos símbolos e da narrativa na configuração da identidade, dedica o filósofo a sua via longa que o vai levar a distinguir, contra o naturalismo de alguma psicologia, dois sentidos de identidade: a identidade idem e a identidade ipse..$^{38}$ Mesmidade e ipseidade, são dois pólos irredutíveis de mim mesmo, habitualmente não considerados e que se podem caracterizar por meio de dois termos descritivos e emblemáticos: o carácter e a manutenção da palavra dada. A distinção entre idem e ipse tem, pois, como intuito fundamental mostrar-nos que a identidade da pessoa surge apenas no fim de toda uma actividade de doação de sentido ao seu vivido, isto é, de unificação deste numa história (peripeteia) que faça sentido. Ricœur assume aqui a herança de Kierkegaaard que punha absolutamente em causa a ideia clássica de uma identidade pessoal substancial para fazer dela um acto de unificação do vivido, um acto de compreensão de si que deve constantemente voltar a acontecer. A designação de idem e ipse aparece, pela primeira vez na obra Soi-même comme un autre com o propósito de explicitar o que realmente se mantém numa pessoa, ao longo do tempo, de tal modo que se possa dizer que há nela um núcleo de si mesmo, isto é, uma identidade, apesar da distensão temporal. O carácter diz respeito à identidade idem, ao que eu herdo com o meu corpo, um genótipo ou o conjunto de traços imutáveis que em qualquer pessoa se mantêm ao longo do tempo, por mais diferente fisicamente que ela possa parecer.

Quanto à ipseidade, Ricœur, define-a, pelo contrário, pela forma de reflexividade que caracteriza o traço ético mais notável da humanidade: "apesar de o meu desejo poder mudar, apesar de eu poder mudar de inclinação, eu manterei a palavra", ${ }^{39}$ o que significa: eu manter-me-ei. Existe, de facto, um modelo de permanência no tempo, (diz-nos o filósofo) diferente do carácter. "É o da palavra mantida na fidelidade à palavra dada. Manter a palavra diz uma manutenção do si mesmo que não se deixa inscrever, como o carácter, na dimensão do qualquer coisa em geral, mas apenas na do quem". ${ }^{40}$ Quer dizer então que, ao contrário do carácter, esta identidade expressa pela promessa não exige um suporte material, é uma outra forma de permanência no tempo, profundamente ética e que inclui em si a alteridade; representa o advento da dimensão fiduciária que deve estar na raiz de todo o laço social.

Tal é, de facto, o significado da ipseidade: poder responder à confiança que o outro deposita em mim, reconhecer-me como alguém com que o outro pode contar, porque ajo de forma idêntica, ao longo do tempo e sou, por isso mesmo, capaz ainda de salvaguardar a instituição da linguagem. ${ }^{41}$ Isto é, não

38 Idem, Soi-même comme un autre, Paris, Seuil, 1990, pp. 140-150.

39 Idem, ibidem, p. 149.

40 Idem, ibidem, p. 148.

41 Idem, ibidem, p. 149. 
sou troca-tintas, alguém que compromete a relação intersubjectiva e próprio sentido das palavras.

Nesta forma de consideração da identidade encontramos uma pista aberta pela hermenêutica de Ricouer para a psicoterapia e podemos perguntar se a noção de personalidade habitual na psicologia se dá conta destas duas dimensões. Por outras palavras, não lidarão os psicoterapeutas apenas com o carácter esquecendo a outra dimensão eminentemente ética, da identidade? Ora, a leitura de Soi-même faz-nos pensar, se não seria de fazer da formação da ipseidade o telos da prática terpêutica. ${ }^{42}$

Claro que esta ipseidade supõe a narrativa, o poder contar a história da sua vida e nela situar-se como personagem. E também sabemos que certos doentes, nomeadamente os esquizofrénicos, têm dificuldades sérias em reconhecer-se como sujeito único de múltiplas experiências. E que o melancólico se fecha habitualmente no passado. Como pensar então à luz destas noções de Ricœur a perda de identidade?

Outra das grandes pistas que a filosofia de Ricœur abre à psicoterapia existencial paece-me ser aquela que tem a ver com a sua distinção entre dor e sofrimento. Para o filósofo a dor diz respeito aos afectos sentidos localmente nos órgãos particulares do corpo ou mesmo em todo o corpo e o sofrimento aos afectos que se abrem à reflexividade, como sejam os que têm que ver com a linguagem, com a relação a si mesmo, com a relação ao outro, ao sentido, e à capacidade de questionar. Por outras palavras, o sofrimento diz respeito ao comprometimento da minha capacidade de agir. ${ }^{43}$ Afecta o homem capaz. Assim às quatro modalidades do homem capaz correspondem em Ricœur quatro figuras que dizem a incapacidade humana, logo, o seu sofrimento: quando o meu poder de falar, de agir, de contar a história da minha vida e de me imputar as acções de que sou actor está atingido, surge o sofrimento e o mal. ${ }^{44}$

Ora, a hermenêutica do mal, tal como a clínica, parte dos sinais do sofrimento para o entender, logo da sua linguagem misturada de emoção. Ajuda-nos a perceber a experiência terapêutica que também se baseia no discurso narrativo: o doente conta o que não compreende, sonhos, episódios do passado e conta até que compreenda o que conta. A doença consiste numa decomposição da função simbólica e toda a tarefa do terapeuta consiste em introduzir de novo o paciente na comunidade simbólica e linguística. ${ }^{45}$

42 Cf. Gilbert, M., L'identité narrative. Une reprise à partir de Freud de la pensée de P. Riccur, Genève, Labor et Fides, 2001, p. 261.

43 Ricœur, P., Soi-même comme un autre, p. 223: "La souffrance n'est pas uniquement définie par la douleur physique, ni même par la douleur mentale, mais par la diminution, voire là destruction de la capacité d'agir, du pouvoir-faire, ressenties comme une atteinte à l'intégrité du soi."

44 Gilbert, M., op. cit., p. 264.

45 Idem, Autour de la psychanalyse. Écrits et conférences, Paris, Seuil, 2008, p. 281. 
A hermenêutica pode assim iluminar a clínica pela compreensão semântica do sofrimento, que parece estar na base desta. Para a hermenêutica, de contexto ricoeuriano, segundo M. Gilbert, ${ }^{46}$ os sinais do sofrimento podem repartir-se então segundo dois eixos fundamentais: o primeiro, diz respeito à relação entre o sujeito e o outro. $\mathrm{O}$ segundo à relação agir-sofrer. Só os homens que agem podem, de facto, sofrer; o homem é, assim, um ser simultaneamente agente e sofredor. Então o que há que descortinar são: a) no primeiro eixo, os sinais que indicam uma alteração da relação com o outro e consigo mesmo (solidão do sofrer: o outro não pode compreender-me; baixa de auto-estima); b) no segundo: as feridas que impedem a realização do meu poder designar-me, do meu poder agir, do meu poder narrar-me e poder ainda ser imputável.

Concluindo: a hermenêutica ricoeuriana do homem capaz acrescenta à perspectiva da Daseinsanalyse novas e importantes dimensões. São elas: a) uma fenomenologia da vontade que persegue, a partir da realidade corpórea do existir, o modo como o homem se faz um ser capaz e atesta as suas possibilidades, apesar do conflito e da desproporção que o constituem. b) uma análise semântica da linguagem da alienação, como uma linguagem muito particular: simbólica, metafórica. Mancha, pecado e culpabilidade, por exemplo, são os três grandes símbolos do sofrimento presentes nas narrativas ocidentais, que Ricœur analisa na Simbólica do mal. Eles relatam a experiência ancestral do mal e da alienação e o modo de os expiar e chamam ainda a atenção para o tipo de linguagem em que se expressa esta experiência limite. Mostram-nos também que tal experiência não se dá de outro modo à percepção. c) A mediação da analítica do ser-aí por uma via longa de análise da realidade da interacção e pela da sua semântica própria, isto é, pela aprendizagem da dimensão simbólica da linguagem, do seu modo de funcionamento e dos seus efeitos ontológicos. Chamo símbolo, diz-nos Ricœur, para o distinguir da noção de símbolo, mais genérica, de E. Cassirer, "a toda a estrutura de significação, em que um sentido directo, primário, literal designa para além de si um outro indirecto, secundário, figurado que não pode ser alcançado senão mediante o primeiro". ${ }^{47}$

Com Ricœur percebemos que a alienação exige a compreensão de uma linguagem muito própria, simbólica e que estamos perante um símbolo, quando a linguagem, produz signos de grau composto, em que o sentido não contente com a designação de alguma coisa, designa ainda um outro sentido que apenas pode ser entendido mediante a visada do primeiro. ${ }^{48} \mathrm{O}$ símbolo, que Ricœur encontra, com a sua meditação sobre o mal, mostra-nos que há coisas que não podem ser ditas pela linguagem descritiva ou unívoca, nomea-

${ }^{46}$ Cf. Gilbert, M., op. cit., pp. 258-266.

${ }^{47}$ Idem, Le conflit des interprétations, p. 16.

${ }^{48}$ Idem, De l'interprétation, Essai sur Freud, Paris, Seuil, 1965, p. 25. 
damente o sofrimento. Porquê? Porque todo o sofrimento é sempre uma experiência de contraste, entre o que é agora, e contra o qual protesto, e o que devia ser, em vez do mal. Daí a necessidade do símbolo, uma linguagem que eleva o sentimento à articulação do sentido, e que apenas actua quando a sua estrutura é interpretada. ${ }^{49}$

Não há símbolo sem interpretação, uma vez que sempre que "[...] um homem sonha, profetiza ou poetiza, um outro se levanta para o interpretar; a interpretação pertence, de forma originária ao pensamento simbólico e ao seu duplo sentido". ${ }^{50}$ É, de facto, pela interpretação que o símbolo se inscreve no âmbito mais vasto da linguagem; o símbolo é sempre linguagem, é um tipo de linguagem nascente, que hesita na linha divisória entre bios e logos. Dá testemunho da radicação primordial do discurso na vida. Nasce onde a força e a forma coincidem e tem efeitos ontológicos consideráveis.

\begin{abstract}
The aim of this paper is to reflect the contribution of Philosophical Hermeneutics to Psychotherapy. We first start by clarifying the meaning of Philosophical Hermeneutics and by analyzing its object. Second, finding a support in the two most important names of contemporary Hermeneutics, both H.G. Gadamer and Paul Ricœur, we reject the naturalism to which Psychotherapy reduces itself insofar as it does not take into account the close connection between man's world-of-life and its temporal, linguistic and narrative dimension. Indeed, the very center of the contribution of Hermeneutics lies in the constitution of identity through ethical, linguistic and institutional mediation.
\end{abstract}

